\title{
Televisión y medioambiente: la cobertura de la Cumbre del Clima de Madrid en los informativos de Antena 3, Telecinco y TVE
}

\author{
Television and enviroment: covergage Madrid's Climate Summit in Antena \\ 3, Telecinco and TVE Lunchtime News
}

\author{
Dra. Marián Alonso-González \\ Universidad de Sevilla | Calle Américo Vespucio, 27, 41092 Sevilla | España | \\ http://orcid.org/0000-0003-2676-0449 | malonsog@us.es
}

Fechas | Recepción: 15/01/2021| Aceptación: 19/05/2021

\section{Resumen}

La presente investigación analiza la cobertura informativa de la Cumbre del Clima de Madrid por las tres cadenas televisivas con mayor audiencia: Antena 3, Telecinco y TVE, a través de sus informativos de mediodía. El objetivo es determinar los aspectos formales del tratamiento informativo y comprobar si las noticias trasmitidas lo hacen desde un punto de vista pedagógico que permita concienciar sobre la necesidad de tomar medidas para paliar las consecuencias del cambio climático. Para ello hemos empleado un método de carácter mixto en el análisis de las 381 noticias emitidas entre el 31 de noviembre y el 15 de diciembre, con objeto de recoger también las informaciones previas al evento. Los resultados demuestran la importancia informativa otorgada por los informativos a las negociaciones entre los países participantes en la Cumbre, pero también a los informes relativos al medioambiente y el sostenimiento de la diversidad. También se aprecia un creciente interés de los medios por convertirse en aliados en la lucha contra el cambio climático $y$ en ofrecer informaciones fundamentadas, cercanas en el espacio y el tiempo, y alejada de posturas catastrofistas. No obstante, por delante queda el reto de comprobar si las televisiones son capaces de mantener su atención respecto a la crisis climática o si se trata de un hecho puntual y

\begin{abstract}
The present study analyzes the informative coverage of the Madrid Climate Summit in TVE, Antena 3 and Telecinco television news, in its Lunchtime.The object is to determine how the medias has attended this news and check if they are transmitted from a pedagogical point of view that allows raising awareness of the need to take measures to alleviate the consequences of global climate change. For this research, was adopted a mixed method in the analysis of the 381 news items broadcast between November 31 and December 15, in order to also collect information prior to the event. The results show the importance given by the news to the negotiations between the countries participating in the Summit, but also to the reports related to the environment and the sustainability of diversity. There is also a growing interest in the media to become allies in the fight against global climate change and to offer well-founded information, close in space and time, and too far removed from catastrophic positions. However, we still have a challenge before us, verify that televisions are able to stand the climate crisis's attention or if it's a specific event associated to the demand for information of the World Summit.
\end{abstract}


asociado al interés informativo que genera una

Cumbre mundial organizada por España.

Palabras clave: medioambiente, periodismo, cambio climático, noticias, informativos TV.
Keywords: environment, journalism, climate change, news, lunchtime news.

\section{INTRODUCCIÓN}

El cambio climático se ha convertido en un tema prioritario para la población mundial, por delante del terrorismo islámico o de los ataques informáticos. Según el último informe del Centro de Investigaciones Pew Research Center (PRC, 2019), su crecimiento ha sido del $11 \%$ en los últimos seis años, hasta el punto de que el $67 \%$ de la población mundial identifica el cambio climático como la principal amenaza mundial.

Esta preocupación ha provocado que medioambiente y cambio climático comiencen a tener un lugar propio dentro del ámbito informativo. De hecho, bajo la premisa de que una ciudadanía bien informada y concienciada sobre la magnitud de calentamiento global es vital para hacer frente al gran desafío de este siglo, más de 50 medios han suscrito la Declaración de los medios de comunicación frente al cambio climático, una iniciativa que surge de la necesidad de que este problema posea una mayor presencia, tanto de forma cualitativa como cuantitativa, pues el buen ejercicio periodístico es clave a la hora de generar un debate social de calidad.

Aunque la expresión periodismo ambiental empezó a perfilarse en las décadas de 1970 y 1980 (Fernández, 2001), no es hasta 1992, a raíz de la Cumbre de Río de Janeiro, cuando, según Fernández Parrat (2006), se consiguió elevar el grado de concienciación de la opinión pública, llegándose, incluso, a ganar diez premios Pulitzer sobre informaciones ambientales.

En España la atención mediática global sobre el cambio climático y el calentamiento global "describe una trayectoria sinuosa, ya que cuenta con una presencia constante de información en los diarios, pero siguiendo un patrón ciertamente irregular" (Fernández-Reyes, Piñuel y Mariño, 2015, p. 135). La espectacularidad de sucesos como el desastre del Prestige en 2002 hizo "saltar las alarmas sobre la destrucción de la naturaleza y acrecentó la sensibilidad de una opinión pública cada vez más preocupada por el entorno" (Fernández Parrat, 2006, p. 4), no obstante, hasta 2006 la cobertura de este tipo de temas fue bastante escasa. En 2007 se experimenta una fase de ebullición puntual que rápidamente entra en declive, aunque con ondulaciones y con "un episodio puntual que atrajo una cobertura inusual: la cumbre de Copenhague a finales de 2009" (Fernández-Reyes, Piñuel y Mariño, 2015, p. 135).

Desde entonces, y pese a la importancia adquirida por el deterioro ambiental como tópico del discurso público, el interés mediático ha ido decreciendo debido a que, según Mancinas (2013), se conjugan la 5P's enunciadas por Ramón Reig (2010): una publicidad con urgencia por estimular el consumo, la política como cómplice de las grandes corporaciones globales, la producción poniendo en jaque al modelo actual de negocio del periodismo, un público que no exige información veraz y "la propiedad de los medios, que muchas veces coincide con las empresas más reacias a tomar decisiones para evitar el cambio climático" (Mancinas, 2013, p. 247). 
En televisión, el tiempo dedicado a las noticias ambientales en los informativos ha ido creciendo muy lentamente, de un 2\% en 2006 al 3,4\% en 2012 (Francescutti, Tucho e íñigo, 2013) y, no siempre ha guardado relación con "la relevancia social de estas cuestiones" (Picó, 2017, p.91). De hecho, este tipo de noticias suelen copar la actualidad cuando se trata de informaciones relacionadas con catástrofes, desastres naturales o cumbres internacionales, hasta el punto de imponerse un nuevo modelo de noticia televisiva "más relacionada con el entretenimiento y en la que prima el interés de captar cuotas de audiencia” (León, 201, p. 90).

En la actualidad, "casi un tercio de los contenidos emitidos por los informativos diarios se centran en el clima y en el tiempo" (Alonso-González, 2020, p. 331) y, pese a que en su inmensa mayoría suelen "estar relacionadas con los sucesos y catástrofes asociados a los fenómenos meteorológicos" (Alonso-González, 2020, p. 331), se aprecia un creciente interés por los temas medioambientales, sobre todo de aquellos que tienen un cierto peso en la actualidad informativa, es por ello que se informa "mayormente al compás de las Cumbres y publicación de informes científicos del Instituto del Clima" (Rojo y Dudu, 2017, p. 7).

Esta inclusión de la cuestión medioambiental en las escaletas televisivas también responde a una estrategia de marketing social por parte de las cadenas y se integra dentro de su Responsabilidad Social Corporativa, la cual pasa por el desarrollo y cumplimiento de los Objetivos de Desarrollo Sostenibles (ODS), los cuales hacen referencia a las metas relacionadas con el medioambiente y los trabajos sostenibles.

En este sentido, Atresmedia se ha planteado objetivos como aumentar la eficiencia energética, minimizar el consumo de recursos o concienciar a la sociedad sobre la necesidad de cuidar el medioambiente a través de campañas como "Hazte eco". Por su parte, Mediaset ha incluido dentro de su "12 meses, 12 causas" iniciativas como la conservación de nuestras playas, \#StopBasuraleza o "Alas Verdes". También Televisión Española inició en enero de 2020 "RTVE, por un planeta mejor", una campaña corporativa que tiene por objeto concienciar y dar a conocer el compromiso del ente público con los ODS promulgados por la ONU a fin de lograr un mundo sostenible para 2030.

A este respecto, indica Jiménez-Gómez (2017) que la RSC debe también suponer una reestructuración comunicativa, ubicando en el centro a la idea de veracidad, y cita a Lizcano (2009) al indicar que a fin de que la responsabilidad social corporativa no sea sólo retórica social corporativa, es necesario que las empresas determinen con exactitud cuáles son sus emisiones reales, en qué medida influyen en el cambio climático, cómo van a reducir sus emisiones y en qué forma van paliar sus responsabilidades en el cambio climático.

\subsection{Emergencia climática y Cumbre del Clima 2019}

La 25 edición de la Cumbre del Clima (COP25), celebrada en Madrid entre el 2 y el 15 de diciembre de 2019, ha supuesto un gran esfuerzo organizativo para España ya que, debido a la convulsa situación de Chile, el país anfitrión, se ha tenido que cambiar de escenario y organizar contrarreloj un evento en el que se han dado cita más de 20.000 personas de 195 países y más de 50 jefes de estado, gobierno y altos mandatarios de organizaciones internacionales.

Pese al éxito organizativo y de asistencia, la cumbre no ha estado exenta de dificultades, sobre todo a nivel de conclusiones y compromisos, lo que ha provocado que los encuentros se hayan prolongado dos días más de lo previsto, habiéndose convertido en la cumbre más larga de la 
historia, pero sin resultados efectivos, ya que los casi 200 países asistentes se han limitado a aplazar la cuestión de la regulación de los mercados de emisiones de carbono a la reunión de Glasgow (Escocia), suspendida debido a la crisis de la COVID-19.

El objetivo de esta Conferencia de Partes era estabilizar las concentraciones atmosféricas de gases de efecto invernadero con objeto de impedir que provoquen cambios nocivos en el sistema climático, y para ello es importante modificar las áreas que requieren una acción global inmediata.

Según los expertos, "la crisis climática está extremadamente vinculada al consumo excesivo del estilo de vida rico" (Ripple et al., 2019). Un estilo de vida que ha provocado que durante 2019 más de 11.000 científicos hayan declarado la "emergencia climática" en un informe que recoge seis medidas concretas para hacer frente a la amenaza del cambio climático y que pasan por la necesidad de un cambio de modelo energético, reducir los contaminantes de vida corta (carbono negro y metano, entre otros), restringir el desbrozamiento masivo de los bosques, consumir menos carnes y más vegetales, revertir el modelo energético y el control demográfico.

Según la Convención Marco de las Naciones Unidas, que entró en vigor en 1994, se entiende el cambio climático (CC), como el cambio de clima atribuido directa o indirectamente a la actividad humana que altera la composición de la atmósfera mundial y que se suma a la variabilidad natural del clima observada durante periodos de tiempo comparables.

Desde el punto de vista meteorológico, el cambio climático es producido por el denominado efecto invernadero que provoca el calentamiento global y por ello se establece como objetivo "lograr la estabilización de las concentraciones de gases de efecto invernadero en la atmósfera con el fin de impedir interferencias atropogénicas peligrosas en el sistema climático" (CMNUCC, 1992).

Para reducir las emisiones y asegurar la producción de alimentos y un desarrollo económico sostenible, en 1995 se firma el Protocolo de Kyoto, cuyo primer periodo de compromiso se desarrolló entre 2008 y 2012, mientras que el segundo se inició en 2013 y finalizó en 2020.

En España, la conciencia ecológica despierta en la década los 70 de la mano de Félix Rodríguez de la Fuente. Gracias a su programa "El hombre y la tierra", surgen las primeras iniciativas ecologistas que han logrado grandes hitos como el rescate del lince ibérico, la recuperación del oso pardo y el constante crecimiento de los Parques Naturales y de la red Natura 2000.

A pesar de llevar "alrededor de 20 años de políticas públicas medioambientales orientadas a reducir emisiones de gases efecto invernadero (GEI) o mitigadoras del calentamiento global o del cambio climático" (Rojo y Dudu, 2017, p. 2), son los nacidos entre 1981 y 1995 los que han dado un vuelco a la lista de prioridades ciudadanas y han demostrado ser capaces de actuar en situaciones concretas.

La generación Millennial se ha encontrado con un mundo afectado por el cambio climático y cuyos efectos son más que evidentes, de manera que el medioambiente se ha convertido en la causa que más merece la pena defender para la mayoría de los jóvenes españoles, por encima de cuestiones como la igualdad. Este sentir ciudadano tiene un fiel reflejo dentro de la agenda política de los estados, los cuales intentan dar respuesta a las inquietudes civiles apostando por un cambio en el modelo de transporte y por una economía circular. 
En España, la importancia concedida a este tema ha quedado concretada en la creación de un Ministerio para la Transición Ecológica cuyas prioridades pasan por la creación de una Ley de Cambio Climático con objetivos cuantificables de reducción de emisiones, la creación de una hoja de Ruta de descarbonización y cierre progresivo de las centrales de carbón, el impulso a un modelo de "Fiscalidad Verde", la creación de un fondo especial para el cambio climático y la adopción de medidas para hacer frente a la contaminación por plásticos.

\subsection{Periodismo y medioambiente}

La cuestión del cambio climático ha conseguido afectar a un público amplio porque su formulación se ajusta a los cinco parámetros enunciados por Cobb y Elder (1972). Por una parte, se trata de un problema nuevo, duradero en el tiempo y que se enuncia en términos simples: la industrialización, la contaminación y nuestro estilo de vida provocan el cambio en el clima. A todo ello se suma la ambigüedad de la definición del problema y su carácter imperfecto, es decir, las alteraciones que el ser humano genera en el planeta son múltiples, al igual que sus consecuencias, algunas desconocidas hasta el momento.

A todo ello, Escudero, Lois y Martí (1999, p. 69), añaden que para que un tema de debate social surja "es necesario que se produzcan situaciones inesperadas que generan preocupación a la colectividad", tal es el caso de largos periodos de sequía, inundaciones o el descubrimiento del agujero en la capa de ozono, problemas, todos ellos, que provocan que la mentalidad colectiva tome consciencia de que los recursos son limitados y el planeta finito.

El futuro del planeta se ha convertido en un tema prioritario para políticos y ciudadanos y, es por ello, que los medios de comunicación muestran cada vez una mayor preocupación sobre este tema. En este sentido, se hace necesario conocer qué se cuenta y cómo para:

Entender las actitudes sociales respecto a asuntos de gran calado como el cambio climático partiendo de la base de que un correcto tratamiento informativo fomentará un mejor conocimiento de los temas ecológicos, una mayor concienciación ambiental social, e incidirá en la transformación de valores, actitudes y comportamientos sostenibles (Mercado, 2013, p.123).

El desarrollo de la especialización periodística y la expansión de Internet han sido determinantes para que las informaciones medioambientales tengan cabida dentro de la agenda setting de los medios, pese a que el tratamiento informativo no es uniforme y varía según los países (Fahn, 2008). Sin embargo, es imprescindible ejercer un periodismo en profundidad que "ha de fundamentarse en una documentación exhaustiva, narración de antecedentes, consecuencias y actores implicados, análisis del hecho ambiental e inserción de acontecimientos en el contexto adecuado" (Bacheta, 2012).

De hecho, el principal problema reside en el carácter difuso del mismo, el cual permite que las fuentes informativas jueguen un rol influyente en la configuración de las agendas y los discursos de los medios.

Esta idea entronca con la apuntada por Ladle, Jepson y Whittaker (2005) al subrayar que las noticias sobre el cambio climático están instrumentalizadas y se trasladan a la escena política. Es decir, "tanto ONGs, como líderes de opinión y políticos aprovechan la información sobre cambio climático para mover mediáticamente sus intereses" (Ladle et al., 2005, p. 239). 
Esto explicaría por qué el concepto de cambio climático está relacionado con "predicciones alarmistas y tintes sensacionalistas que han conseguido la vulgarización del conocimiento sobre el tema prescindiendo de una información con un enfoque y tratamiento adecuado, dejando de lado la exageración y el dramatismo en exceso" (Sánchez et al., 2012, p. 115).

Cuando las noticias prescinden del sentido informativo, es frecuente encontrar noticias dramatizadas e inexactas que se refieren a un escenario altamente improbable, según Lomborg (2003), quien, además, resalta la discrepancia entre la información suministrada por los medios y la divulgada directamente por las propias fuentes científicas.

En esta misma línea, Kolberte (2006) señala que la combinación de la pretensión de los científicos de que sean las cifras y los datos quienes hablen por sí mismos y la tendencia periodística a buscar grandes titulares y testimonios que cuenten el tema, resulta comunicativamente explosiva. Es por ello, que se hace necesario sentar las bases de cómo debe ser la cobertura informativa de la cuestión climática pues, un tratamiento inadecuado motivaría informaciones en las que abunden expresiones "dramatizadas e inexactas" (Cáceres et al., 2012, p. 115).

A este respecto, Heras, Meira y Benaya (2016, p. 56) defienden la necesidad de evitar que el cambio climático se convierta en "una sucesión de informaciones alarmantes o sombrías" que de ningún modo conducirían a una mayor atención o implicación por parte de la sociedad. Una idea que también defienden Águila y Teso (2011), quienes señalan que hay que cambiar los criterios que rigen la actualidad medioambiental en los medios: las catástrofes naturales, atribuibles en mayor o menor medida a la alteración del planeta; los comunicados o actos públicos emitidos por la comunidad científica, y la agenda política, como es el caso de la cobertura de una cumbre del clima.

Precisamente es una cumbre, la de Bali (2007), la que informativamente marca un antes y un después en la cuestión climática, pues supuso un "aumento sin precedentes de la atención mediática a este problema medioambiental" (Lopera, 2013, p. 145). Desde entonces, los picos de atención al cambio climático suelen coincidir con eventos de política internacional. De hecho, en 2009, coincidiendo con la celebración de la COP 15, se concentra el mayor número de estudios publicados sobre el cambio climático de la historia (De Rueda, 2014, p. 178).

Lamentablemente, esta tendencia no duró mucho y, desde entonces, ha disminuido el envío de periodistas a cubrir estos eventos mundiales y también la presencia de periodistas occidentales, mientras que "Ios reporteros de países en vías de desarrollo se han multiplicado en los últimos años, incluso han llegado a superarlos en presencia" (Arévalo, 2012, p. 7).

Otra tendencia generalizada en la cobertura informativa de la COP es que "la mayoría de las fuentes informativas corresponden a instituciones políticas nacionales" (Nossek y Kunelius, 2012, p. 72), así como que los medios se centran más en destacar el origen del problema que en aportar soluciones al mismo y esto puede motivar apatía e indiferencia.

A nivel televisivo, el medio preferido por el $63 \%$ de los españoles para informarse de las cuestiones de interés (Digital News Report, 2020), la cobertura informativa de las cumbres del clima ha sido objeto de estudio por Águila (2016), Ertivi y de Lara (2012), Cáceres, Sánchez Calero y Morales (2012), León y Ertivi (2013), de hecho, estos últimos analizaron la cobertura 
de la Cumbre de Copenhague, centrándose en el "escándalo del Climategate, el robo de correos electrónicos a científicos del clima” (2013, p. 1471).

Sin embargo, más allá de Durban 2011 no existen estudios sobre el tratamiento informativo otorgado a la cuestión climática y a los grandes eventos relacionados con la misma, es por ello, que tomando como referencia las conclusiones de estudios precedentes en este ámbito, el presente trabajo busca analizar cómo tres de las principales cadenas de televisión españolas han informado sobre Cumbre del Clima de Madrid 2019, si se han generado encuadres o marcos de interpretación de la realidad, de qué tipo han sido, si se ha logrado un equilibrio informativo alejado del dramatismo que suele acompañar a las informaciones climatológicas y si las noticias han sido transmitidas desde un punto de vista pedagógico que permita concienciar a los españoles en la necesidad de tomar medidas para paliar las consecuencias del cambio climático.

\section{OBJETIVOS}

La presente investigación tiene por objeto cuantificar el peso específico que la información medioambiental ha tenido dentro de los informativos de la cadena pública TVE y las privadas Antena 3 y Telecinco durante la celebración de la vigésimo quinta edición de la Cumbre Mundial del Clima.

Partiendo de la hipótesis de que la relevancia del evento celebrado en España ha supuesto un incremento del flujo comunicativo de noticias medioambientales y que ello implica un esfuerzo por parte de las cadenas televisivas por ayudar al receptor a entender correctamente el fenómeno, pretendemos determinar la temática y tipología de las informaciones emitidas, la duración de las noticias, así como analizar el tono empleado en las mismas, a fin de comprobar si el cambio climático es aludido a merced de la cobertura mediática de los asuntos relativos a la destrucción de la naturaleza y a los cambios de temperatura debido a las condiciones ambientales.

De manera complementaria, intentaremos establecer los temas que prevalecen en la cobertura televisiva, los encuadres que emplearon las cadenas a la hora de abordar la cuestión climática, y las consecuencias que destacan.

\section{METOdOLOGÍA}

Para la consecución de los objetivos anteriormente marcados, y con objeto de verificar o refutar nuestra hipótesis de partida, hemos realizado el seguimiento de la información relativa al tiempo emitida en los programas informativos de mediodía de Antena 3, Telecinco y TVE, por ser los espacios con un mayor número de espectadores. Informativos Telecinco ostenta el liderato con 1.973 .000 de espectadores de promedio por emisión ${ }^{1}$ y en la sobremesa de los fines de semana, mientras que Antena 3 es la más vista en la sobremesa de lunes a viernes (17,6\%), seguida de TVE con un (12,9\%) (Barlovento, 2019).

A fin de obtener unos resultados lo más completos posibles hemos procedido al estudio de 381 noticias emitidas entre el 31 de noviembre y el 15 de diciembre, con objeto de recoger también las informaciones previas al evento. En un primer momento, el estudio contemplaba

\footnotetext{
${ }^{1}$ Ponderación de las ediciones de sobremesa y noche de lunes a domingo
} 
como fecha de finalización el 13 de diciembre, pero debido a que la Cumbre y sus conclusiones se alargaron 48 horas más, decidimos ampliar en dos días nuestro periodo de estudio.

Para el desarrollo de nuestro estudio hemos elaborado una ficha en la que se recogen los siguientes aspectos:

1. Duración de las noticias y lugar que ocupa dentro de la escaleta del informativo.

2. Peso específico de la noticia dentro del conjunto del noticiero, a fin de determinar, la "preeminencia de los temas abordados como noticia sobre otros que no lo son, destacando algunos aspectos de la realidad para hacerlos más notorios" (Teso, 2016: 53).

3. Catalogación de las piezas en función del género periodístico: noticia, entrevista, reportaje o crónica.

4. Identificación del tipo de composición utilizada en la elaboración de las piezas informativas: presentador, presentador + colas (vídeos que sólo contienen imagen y sonido ambiente y cuya locución la pone en directo el presentador), presentador + pieza (combina imagen con locución y sonido ambiente previamente producida), presentador + entrevista, presentador + conexión en directo y presentador + conexión en directo + pieza.

5. Análisis del contenido de las noticias en base a las categorías: meteorología y previsión, riesgo o catastrofismo y sostenibilidad ambiental (Semetko y Valkenburg, 2000; Tankard, 2001; Vicente y López, 2009). Las primeras hacen referencia al tiempo en la península, las segundas son aquellas que tratan esas noticias como si de un suceso se tratase y las últimas son las que intentan adaptar el mensaje de la comunidad científica a una población cada vez más interesada en los efectos y consecuencias del cambio climático.

6. Clasificación de las noticias en base a la temática abordada, y para ello se establecen las siguientes categorías: negociaciones políticas, medioambiente y educación, cambio climático y catástrofes, manifestaciones, el papel de España en la Cumbre, así como noticias exclusivas de la cumbre. Dada la trascendencia otorgada a la activista Greta Thunberg decidimos incluir un apartado que midiera el protagonismo de la misma en el conjunto informativo del COP 25.

7. En base a sus encuadres, y siguiendo las pautas de Nisbet (2009), clasificaremos las piezas informativas en:

- Progreso social y avances científicos.

- Desarrollo económico y competitividad.

- Conflicto y estrategia. Negociación política y posiciones enfrentadas.

- Certidumbre científica. Se da por válido el conocimiento expuesto por los científicos.

- Caja de Pandora. Noticias que hacen hincapié en la necesidad de precaución o acción para enfrentar las catástrofes y las consecuencias fuera de control. 
- Medio camino. Tercera vía entre las opiniones en conflicto (alimentación o moda sostenible).

- Incertidumbre o escepticismo.

- Redición de cuentas públicas y gobernanza. Hace referencia a la acción o inacción por parte de los poderes gubernamentales.

8. Respecto al discurso medioambiental ofrecido por las cadenas, nos basaremos en los dos tipos que Piñuel, Gaitán y Lozano (2012, p. 38-40) señalan propios de este tipo de eventos: el político y de catástrofes. El primero hace referencia al propósito de alcanzar acuerdos o pactos, y en ellas la figura del político aparece como protagonista en los debates y las negociaciones. El segundo explica los fenómenos relacionados con el cambio climático, ofrece un diagnóstico de la situación y expone los escenarios futuros más probables.

A ambas categorías vamos a añadir otras dos más: el discurso informativo "alarmista y catastrofista, centrado en el riesgo de grandes desastres naturales y en la urgente actuación en las esferas de decisión política y económica" (Lorente et al., 2009, p. 326), y uno de corte educativo que, según Teso (2018), debe abordar "las causas, los impactos, pero sobre todo las soluciones, priorizando las medidas que pueden tomarse a nivel individual y colectivo como medida para mitigar el riesgo y asumir la adaptación responsable".

9. En referencia a los impactos del cambio climático procederemos a la identificación del problema, de los responsables y si las consecuencias pueden ser negativas, positivas o debatidas; así como al diagnóstico de las causas, prestando atención a si se plantea alguna recomendación de tratamiento o solución al problema. Asimismo, estudiaremos si el cambio climático aparece asociado a alguna de las categorías identificadas por la Comisión Europea (2020): aumento de las temperaturas, aumento del nivel del mal, catástrofes extremas, daños en la salud, migración, extinción de especies, apartheid climático y consecuencias económicas.

\section{RESULTADOS Y DISCUSIÓN}

Atendiendo al peso específico que estas noticias poseen en el conjunto las tres cadenas, y teniendo en cuenta que el telediario de TVE tiene una duración de 53 minutos, frente a los 34 de Telecinco y Antena 3, las tres cadenas presentan cifras muy similares, siendo TVE la que más tiempo destina a informar sobre la Cumbre $(25,25 \%)$, seguida de Antena $3(22,9 \%)$ y Telecinco (22,5\%).

Por su parte, Antena 3 es la cadena que más noticias ubica en su sumario, hasta un total de 39. Le siguen TVE con 30 y Telecinco con 26. No obstante, si tenemos en cuenta la entidad que las informaciones poseen en cuanto a su duración, sobresale TVE con 133 noticias, seguida de Telecinco (82) y Antena 3 (71).

Las noticias emitidas superan el minuto de duración en más de la mitad de los casos (tres de cada cinco), mientras que un tercio tiene una duración estándar, de entre 30 segundos y un minuto. Solo en el $9 \%$ de los casos encontramos noticias cortas (menos de 30 segundos). 
Tanto el inicio como el final de la Cumbre suponen un hecho periodístico de primer orden para las tres cadenas. Como puede apreciarse en el Gráfico 2, Antena 3 y TVE dedican más de la mitad del informativo (53,6\% y $60,4 \%$, respectivamente) a informar sobre ello. Este interés también resulta evidente el día anterior a la inauguración, dedicándose hasta el 30\% del total de las noticias emitidas.

Este mismo fenómeno se observa en la cobertura informativa realizada por las cadenas radiofónicas, aunque éstas invierten menos tiempo en informar sobre el evento, de hecho, sólo la COPE destinó "uno de cada cinco minutos" de su informativo a este tema (De Sola, 2020, p. 215).

La atención va decreciendo durante el desarrollo de la Cumbre, no obstante, en su ecuador (días 7 y 9 de diciembre), encontramos un incremento informativo que coincide con la Marcha por el Clima y la intervención de Greta Thunberg. Nuevamente, Antena 3 y TVE dedican el 20\% de sus informativos a hablar sobre este tema.

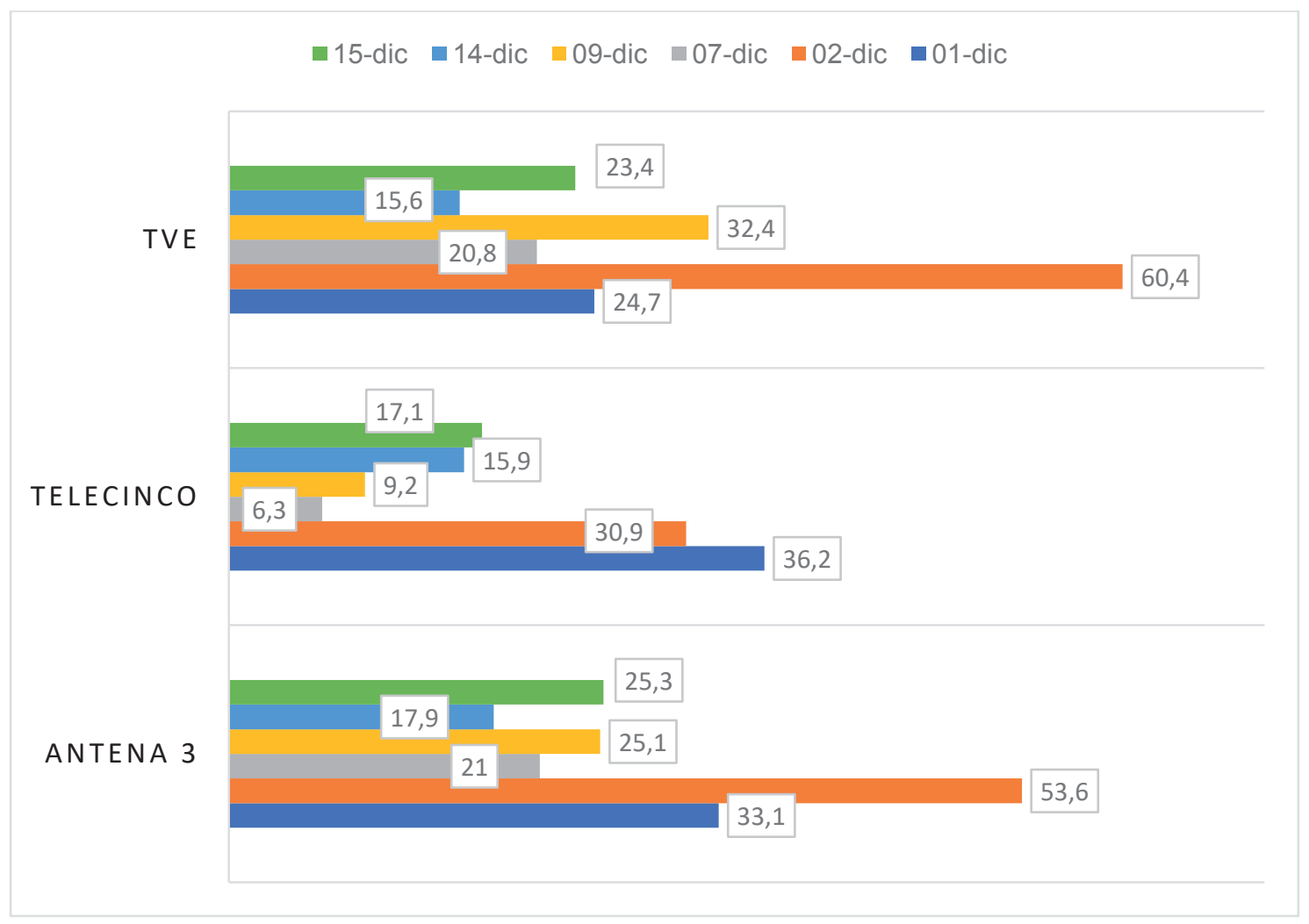

Figura 1. Días en los que se concentra un mayor interés informativo.

Fuente: elaboración propia.

La atención se reactiva los dos últimos días de la Cumbre debido a la falta de conclusiones. La incapacidad para llegar a un consenso provoca un flujo informativo superior al 15\% el 14 de diciembre y cercano al $25 \%$ el 15 de diciembre. Ambos días las noticias estuvieron centradas en la intensa jornada de negociaciones y en el documento final: «Chile-Madrid. Tiempo de Actuar». 


\section{1. $\quad$ Clasificación en base a su contenido}

El 38\% son noticias emitidas son de corte hidrometeorológico y catástrofes relacionadas con el tiempo. En concreto, el 32\% hace referencia al fenómeno atmosférico Dana y el temporal de lluvia y nieve en el Norte de España, mientras que un $6 \%$ se corresponde con desastres naturales tales como las inundaciones en Francia y Estados Unidos, la erupción de un volcán en Nueva Zelanda y los incendios forestales de Australia (Ver Figura 2).

Estas noticias están redactadas en forma de suceso y caen en el sensacionalismo. El relato está plagado de exageraciones y descripciones trágicas de lo ocurrido, además, se incrementa el interés informando de las pérdidas humanas y materiales.

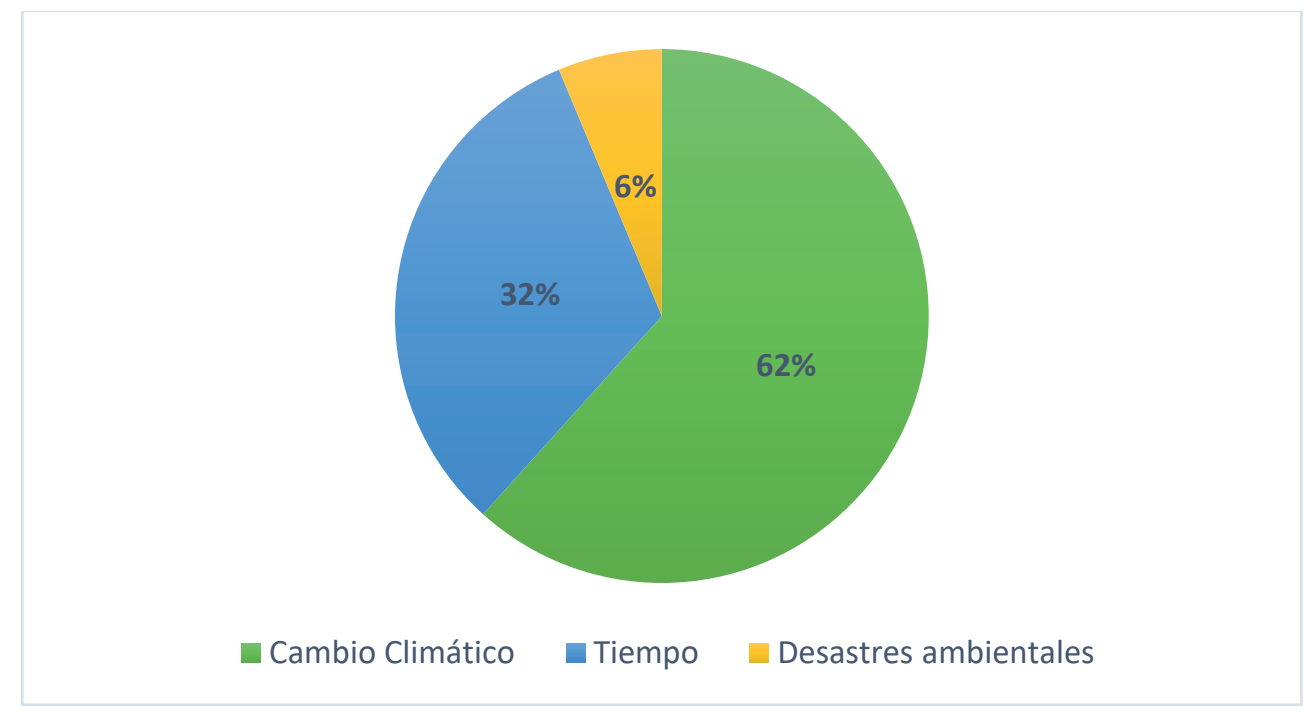

Figura 2. Naturaleza de las informaciones emitidas

Fuente: elaboración propia.

Por cadenas, TVE es la que más información de corte hidrometeorológico ha ofrecido, hasta un total de 47 noticias, lo cual puede deberse a su carácter de servicio público. Le sigue Telecinco (38) y Antena 3 (37).

Por lo general, estas noticias suelen destacarse en el sumario, al contrario de lo que ocurre con las relativas a los desastres naturales, las cuales no son muy abundantes y son de índole internacional. TVE es la que más información proporciona, con 9 piezas, seguida de Telecinco (8) y Antena 3 (7).

Por su parte, las informaciones relativas a la Cumbre del Clima de Madrid constituyen el 62\% de las noticias de índole medioambiental emitidas por estas tres cadenas en sus telediarios del mediodía. Destaca TVE con 107 informaciones, seguida de Antena 3 con 66 y Telecinco con 15. De ellas, Antena 3 es la cadena que más noticias ubica en su sumario 26, frente a las 21 de TVE y las 15 de Telecinco (Ver Figura 3). 


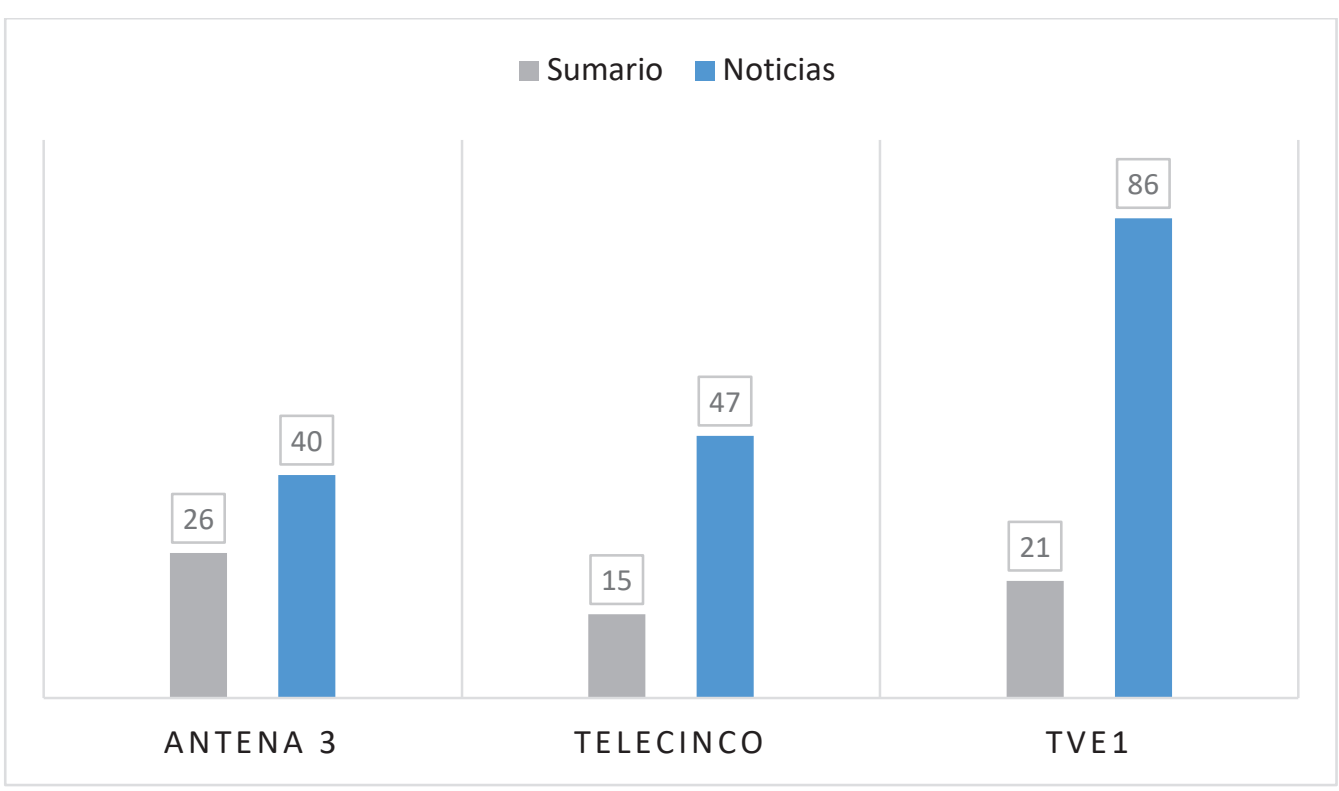

Figura 3. Informaciones emitidas en relación con la Cumbre del Clima Fuente: elaboración propia.

Todas las noticias poseen un gran peso específico dentro de los informativos. Así, mientras que Telecinco y Antena 3 las ubican de forma preferente en los primeros veinte minutos ( $73 \%$ y $67 \%$, respectivamente), TVE lo hace en la segunda mitad del informativo, entre los minutos 20 y 40 del informativo, donde establece un espacio específico dedicado a informar sobre la Cumbre del Clima y que, incluso, posee una cortinilla propia: "Estamos a tiempo".

Como puede apreciarse en Gráfico 6, TVE ubica en su franja central hasta un total de 70 noticias.

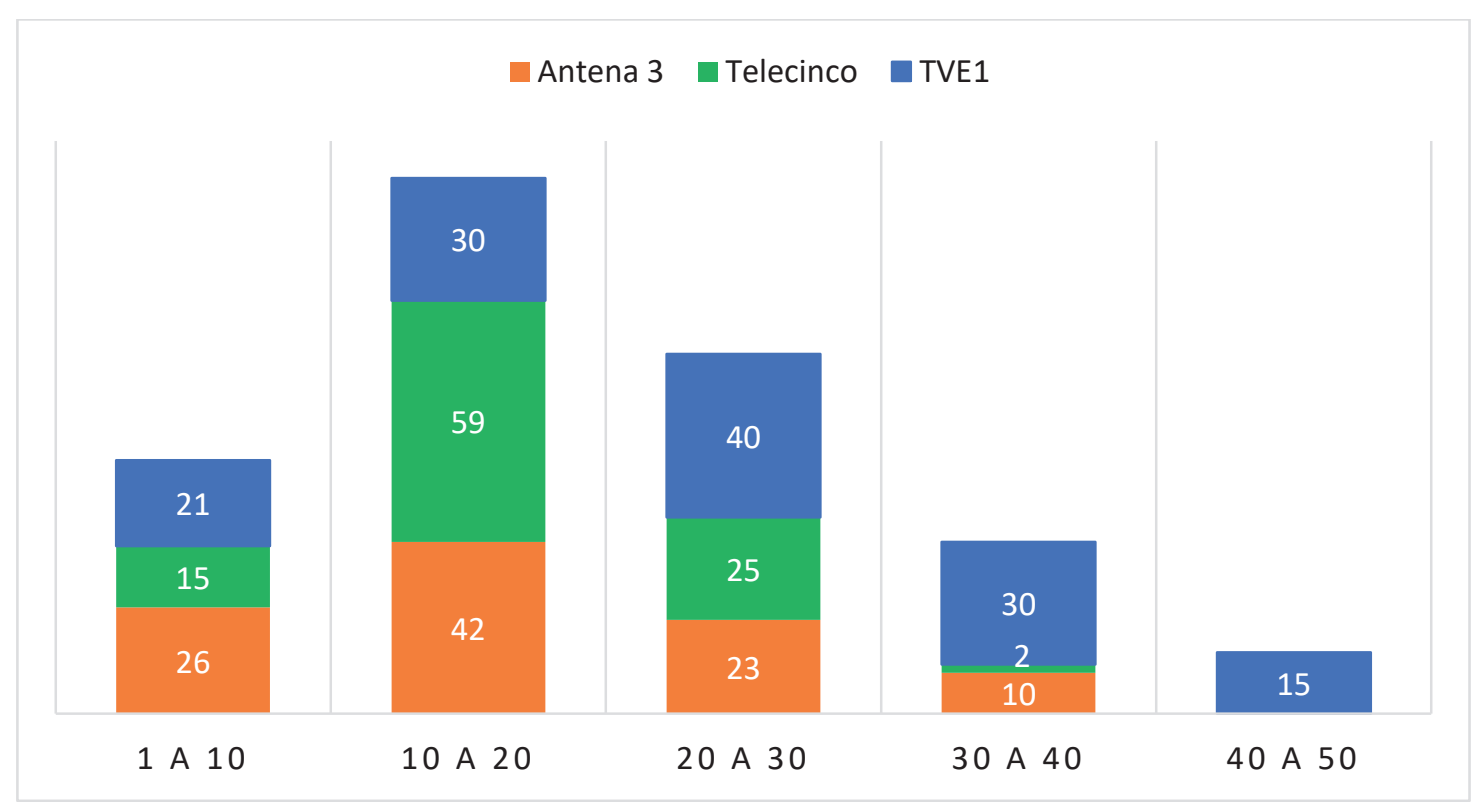

Figura 4. Ubicación de las noticias dentro de la escaleta.

Fuente: elaboración propia. 


\subsection{Catalogación de las piezas en función del género periodístico}

En la cobertura informativa de la Cumbre se aprecia un esfuerzo notable por parte de las tres cadenas televisivas, sobre todo si tenemos en cuenta que la actualidad política de España durante el periodo de nuestro estudio estuvo marcada por las últimas negociaciones para la investidura de Pedro Sánchez como presidente del Gobierno.

El género periodístico más utilizado ha sido la crónica (50\%), seguido de la noticia (43\%), lo cual da una idea del esfuerzo material y técnico realizado por las cadenas por cubrir in situ la Cumbre. Una tendencia que también se observa en la radio, donde la cobertura de tipo informativo es superior al 90\% (De Sola, 2020, p. 216).

Resulta significativo que sólo se haya realizado una entrevista. TVE es la única cadena que recurre a este género informativo. En concreto, entrevista a Eduardo López Puertas, director general de Ifema, que explica el despliegue y esfuerzo realizado para tener listo este evento mundial. En líneas generales, la entrevista se usa para la extracción de totales que permitan reforzar el valor informativo de las piezas informativas.

También llama la atención la escasa relevancia de los reportajes en el conjunto informativo (no llega al $10 \%$ del total), sobre todo, teniendo que en cuenta que éste es un género que "busca guiar con sus interpretaciones a los ciudadanos perdidos en lo que supone la sobreexposición informativa de nuestro tiempo" (Moreno, 2012, p. 827).

La cadena pública vuelve a ser la que en mayor medida aborda este género (Ver Gráfico 8). Sus reportajes tocan temas tan diversos como la descarbonización, la situación de la dehesa en España, el aislamiento térmico de los edificios o la necesidad de concienciar sobre el medioambiente en la escuela.

Entre todos ellos destaca un reportaje elaborador por el Lab de RTVE encargado de diseñar una experiencia interactiva para los espectadores puedan vivir un Telediario del año 2050 desde dos enfoques contrapuestos:

Uno distópico, que refleja cómo se vivirá en el futuro si las distintas naciones y sus ciudadanos no se comprometen a tomar medidas para frenar el cambio climático; y otro utópico, que reflejará el día a día según el mejor de los escenarios con el que trabajan a día de hoy los científicos en sus proyecciones (RTVE, 2019). 


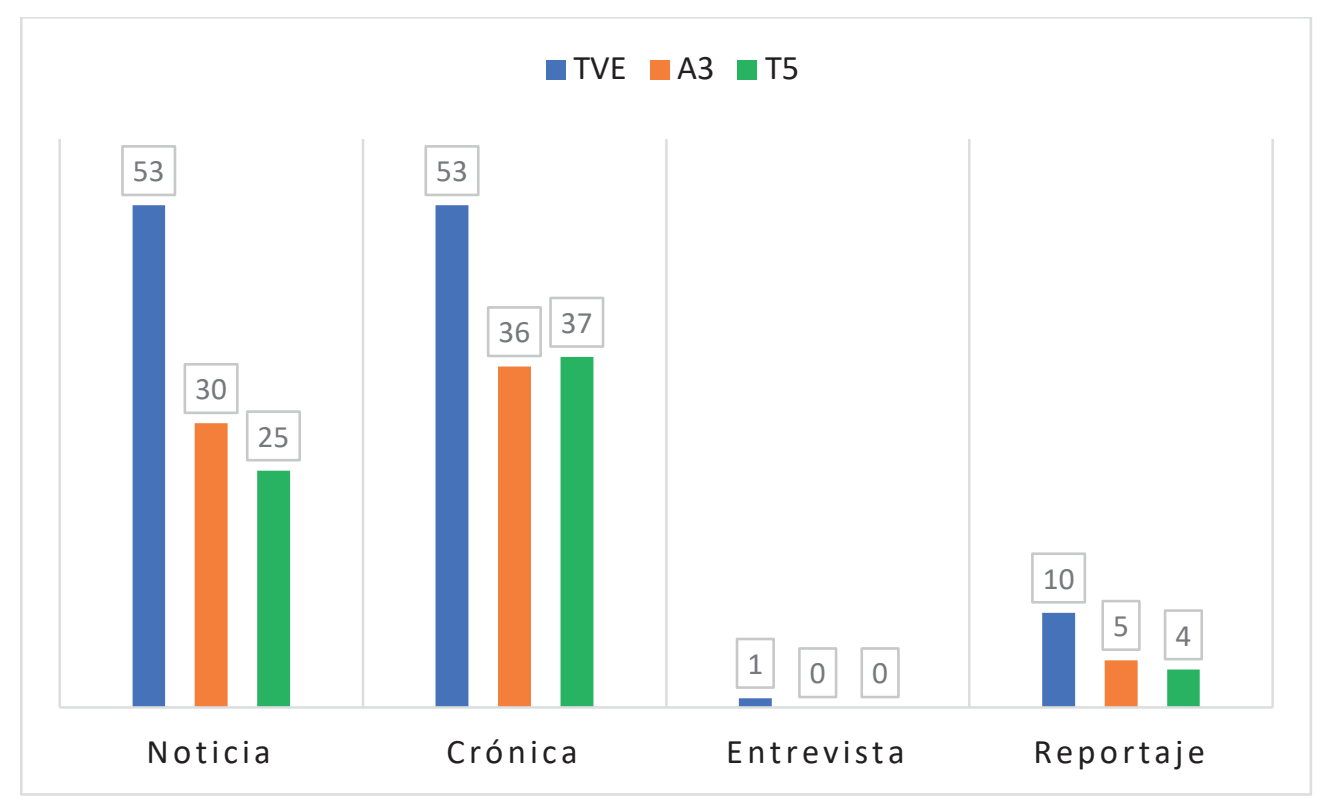

Figura 5. Piezas emitidas durante la Cumbre de Madrid.

Fuente: elaboración propia.

\subsection{Tipo de composición utilizada en la elaboración de las piezas}

Las composiciones más utilizadas son las de presentador + pieza y las de presentador + conexión en directo + pieza, ambos en el $21 \%$ de las ocasiones. Le siguen en importancia, los formatos de presentador + pieza, seguido del presentador + conexión en directo ( $18 \%$ de las veces) y que responde al esfuerzo realizado por las tres cadenas por cubrir presencialmente la Cumbre, de hecho, no se ha detectado ninguna información procedente de agencias (Ver Figura 6). Este dato es significativo, pues en la cobertura informativa de cumbres anteriores (Cancún y Durban) solo el 16\% de las informaciones tuvo la consideración de "propia" (Águila, 2016 , p. 236). Se rompe, pues, con la tendencia informativa decreciente imperante en los medios desde la Cumbre de Copenhague (2009).

El formato presentador + pieza es especialmente significativo en el caso de TVE, que lo usa hasta en 23 ocasiones frente las 8 de Antena 3 y las 12 de Telecinco. 


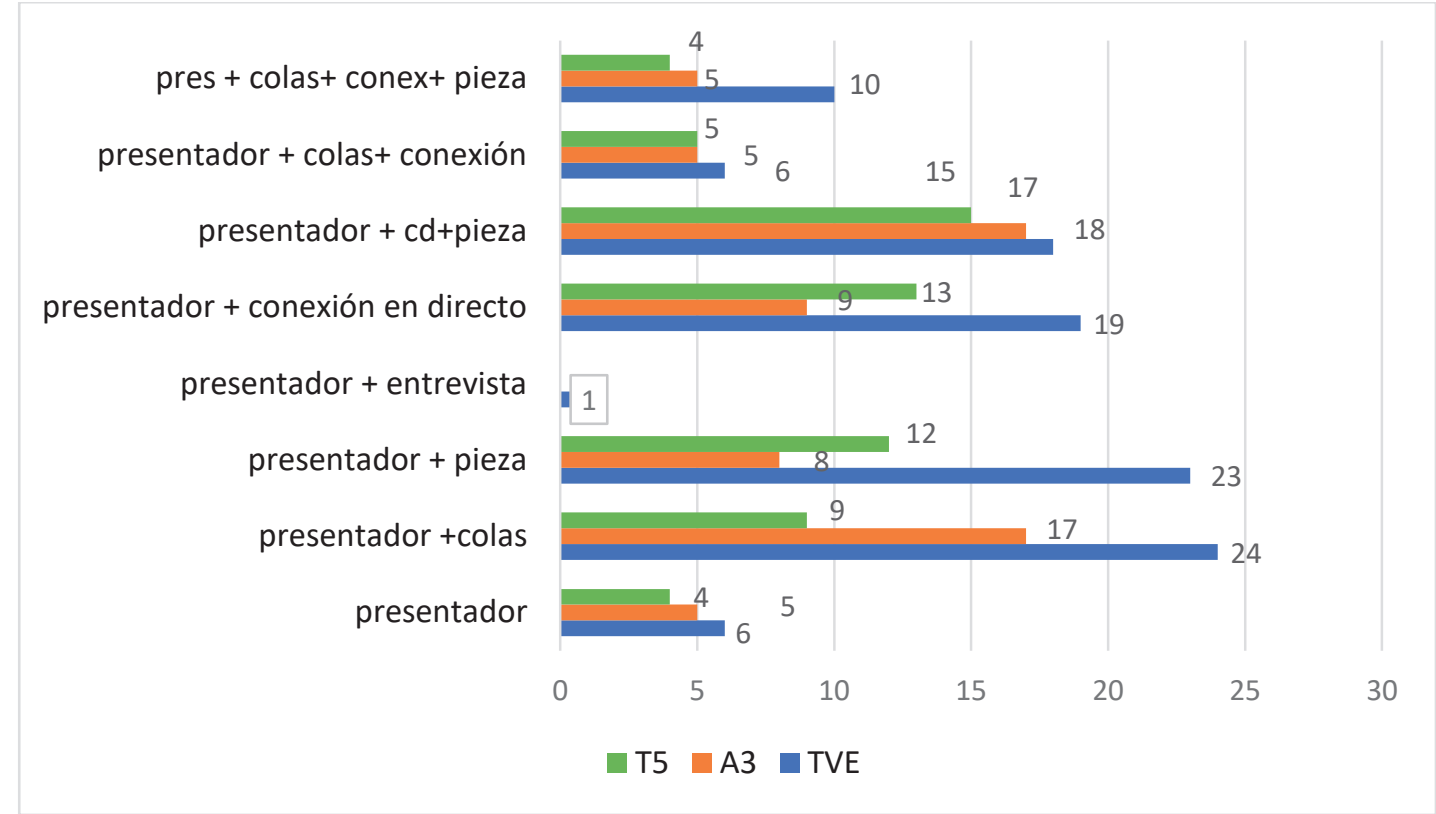

Figura 6. Composición que presentan las piezas informativas.

Fuente: elaboración propia.

\subsection{Temática de las informaciones y tipo de discurso}

En cuanto a la temática, el 28,6\% de las piezas aborda las negociaciones entre los países participantes en la Cumbre, el 19,7\% hace referencia a informes de índole medioambiental, condiciones ambientales y el sostenimiento de la diversidad; el 13,7\% tiene como protagonista a Greta Thunberg, y el 11,9\% habla de catástrofes medioambientales y la necesidad de adoptar medidas para prevenir riesgos futuros.

En menor medida se habla del papel de España en la Cumbre $(1,3 \%)$ y de las manifestaciones de la juventud reclamando un cambio de modelo para evitar el deterioro medioambiental $(3,8 \%)$. Por último, en el apartado de Otros $(8,3 \%)$ hemos consignado temas como el enfrentamiento del actor Javier Bardem y el alcalde de Madrid, la participación de los famosos en la Cumbre, el blindaje policial o las acciones llevadas a cabo por las organizaciones ecologistas.

Al igual que ocurre en la radio, las televisiones han considerado más importante "las negociaciones políticas que los avances científicos y que las demandas sociales" (De Sola, 2020, p. 218), prestando especial atención a la joven activista Greta Thunberg en un porcentaje de piezas similar (13,7\% en televisión y $14,06 \%$ en la radio).

En líneas generales, la temática de las informaciones presenta porcentajes muy similares en las tres emisoras, sólo TVE destaca en el ámbito de la información medioambiental $(26,4 \%)$ gracias sus reportajes. También la cadena pública, quizás por su vocación de servicio público, es la que en mayor medida alude a las consecuencias que tiene el cambio climático, al tiempo que propone medidas a adoptar para revertir la situación (Ver Figura 7). 


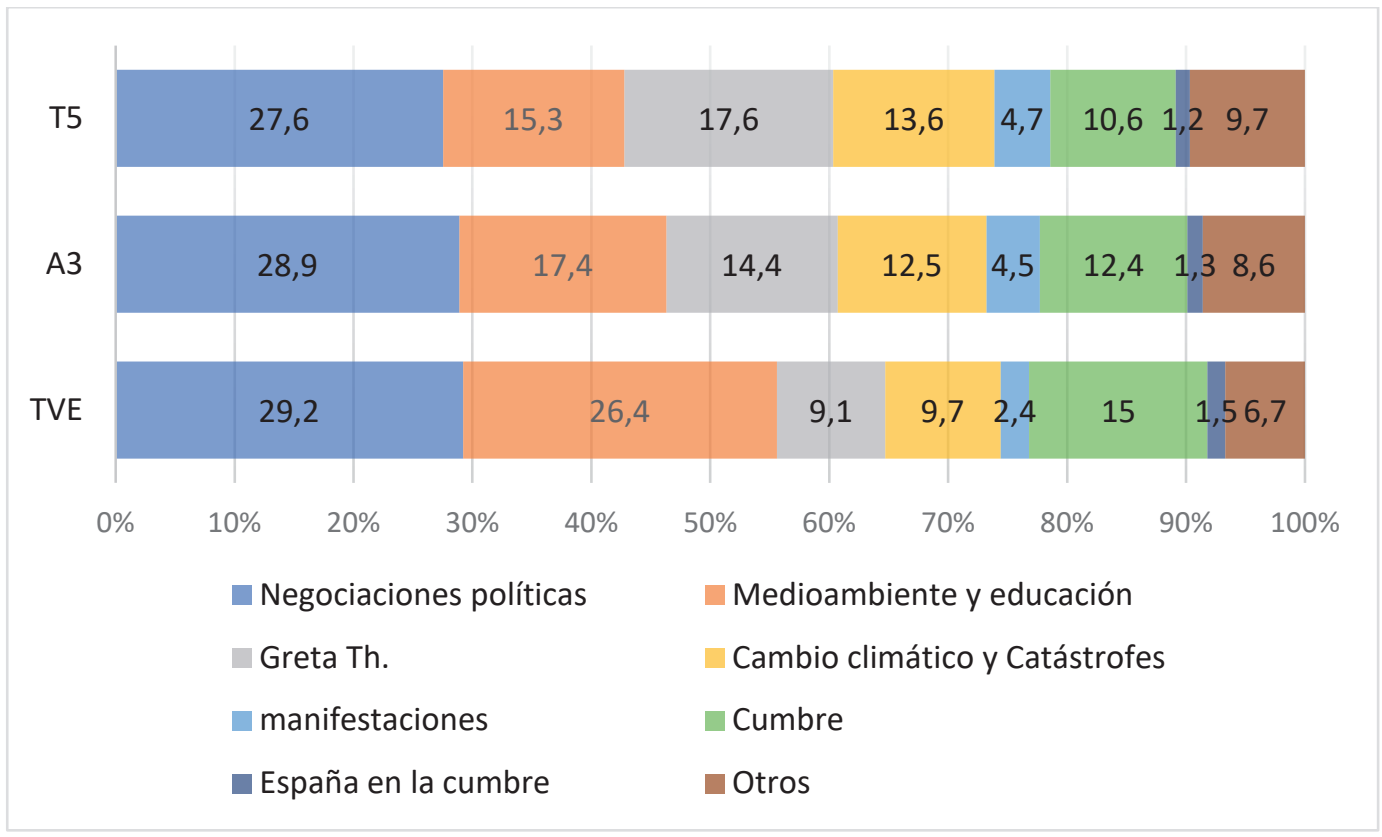

Figura 7. Temática que abordan las cadenas en sus informaciones.

Fuente: elaboración propia.

Las tres cadenas otorgan gran relevancia informativa al viaje, llegada y participación de Greta Thunberg en la Cumbre, en especial las emisoras privadas. La presencia de la joven activista eclipsa, incluso, informaciones relativas al papel de la juventud en la cumbre y las acciones y demandas de los grupos ecologistas.

En cuanto al tipo de discurso, hemos detectado una alocución política caracterizada por el propósito de alcanzar acuerdos o pactos $(34,7 \%)$, un discurso polémico, centrado en la controversia y que tiene como protagonista indiscutible a los activistas $(21,3 \%)$ y un tono catastrofista que roza lo sensacionalista y se centra en los desastres naturales $(8,4 \%)$. Se rompe, pues, la tendencia informativa presente en otras cumbres en las que las noticias referidas al ambiente no tuvieron gran importancia y sí las referidas a catástrofes y desastres derivados de las temperaturas y el calentamiento global, así como las protestas (Águila, 2016, p. 288).

También se aprecia un eminente discurso informativo, de corte educativo, que ofrece un diagnóstico de la situación, explica los fenómenos relacionados con el cambio climático y exponen los escenarios futuros más probables $(41,7 \%)$. Este tipo de discurso es especialmente evidente en Televisión Española.

\subsection{Encuadre informativo}

En base a sus encuadres, el conjunto informativo ha estado dominado por las negociaciones políticas (22\%), un dato que viene a corroborar lo ya demostrado en investigaciones precedentes como la de León y Erviti (2011) sobre la Cumbre de Copenhague en los medios digitales y que sitúa a la política en el centro de la temática medioambiental. La predominancia de los encuadres políticos y científicos también han sido reseñados por León y De Lara (2012) y Fernández-Reyes, Piñuel y Mariño (2015).

Otros aspectos resaltados han sido las informaciones relativas al progreso social y los avances científicos (18\%), así como al desarrollo económico que lleva aparejado un cambio en los 
modos de vida (17\%). Le siguen a corta distancia, las noticias que inciden en la necesidad de precaución o acción para enfrentar las catástrofes, las consecuencias fuera de control (14\%) y aquellas que dan por válido el conocimiento expuesto por los científicos (14\%).

En menor medida se da cabida a informaciones denominadas de tercera vía (5\%) y aquellas que aluden a la rendición de cuentas públicas y la inacción por parte de los poderes gubernamentales (7\%) (Ver Figura 8).

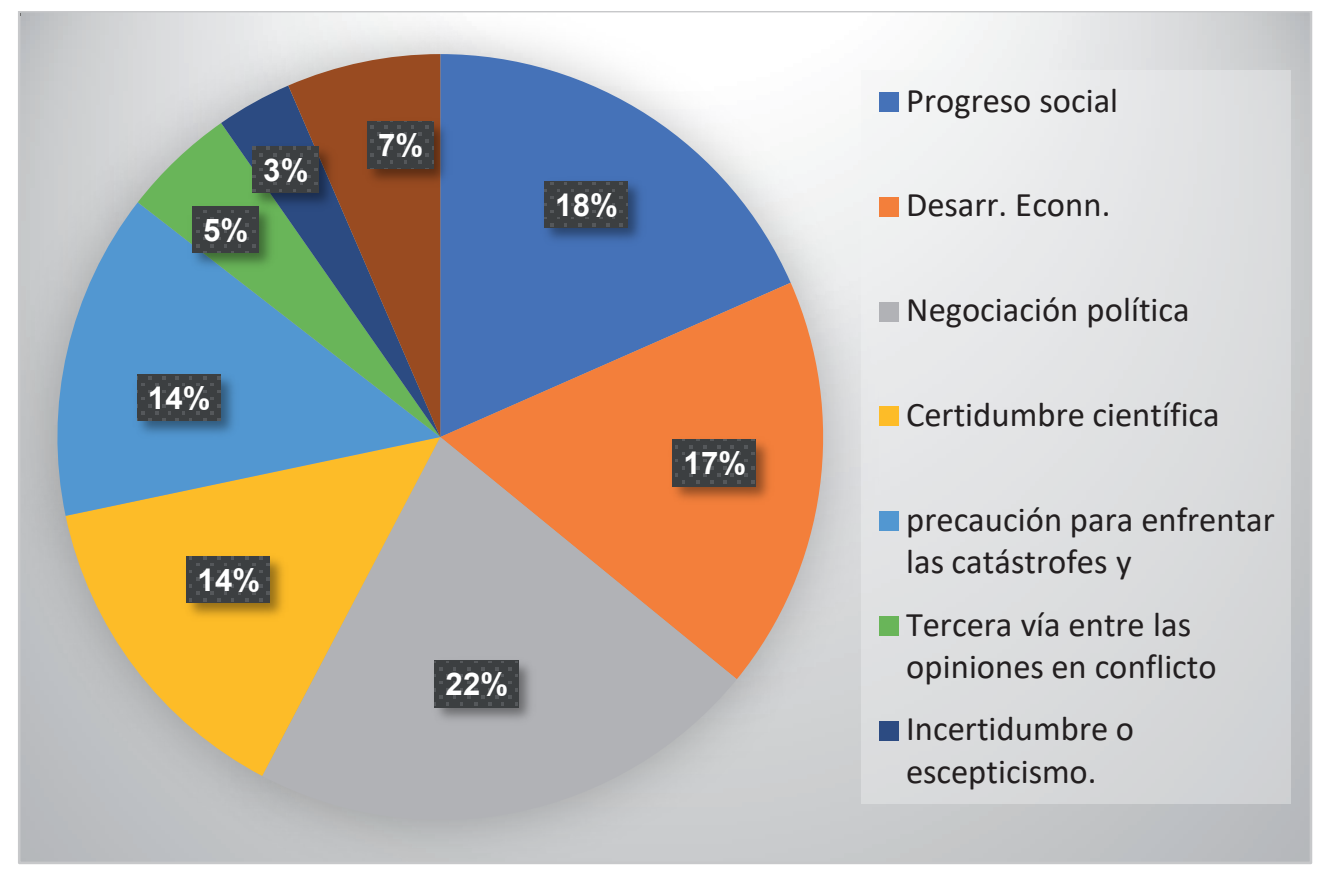

Figura 8. Encuadre informativo transmitido.

Fuente: elaboración propia.

El encuadre informativo es bastante similar en las tres cadenas, quizás lo más sobresaliente es que Antena 3 ha prestado mayor atención a las negociaciones políticas y a la incertidumbre científica, mientras que la cadena pública ha optado por potenciar noticias desde el punto de vista del progreso social (Ver Figura 9). Telecinco se mantiene en la media, optando por encuadres de desarrollo económico y enfatizando las catástrofes asociadas al cambio climático. 


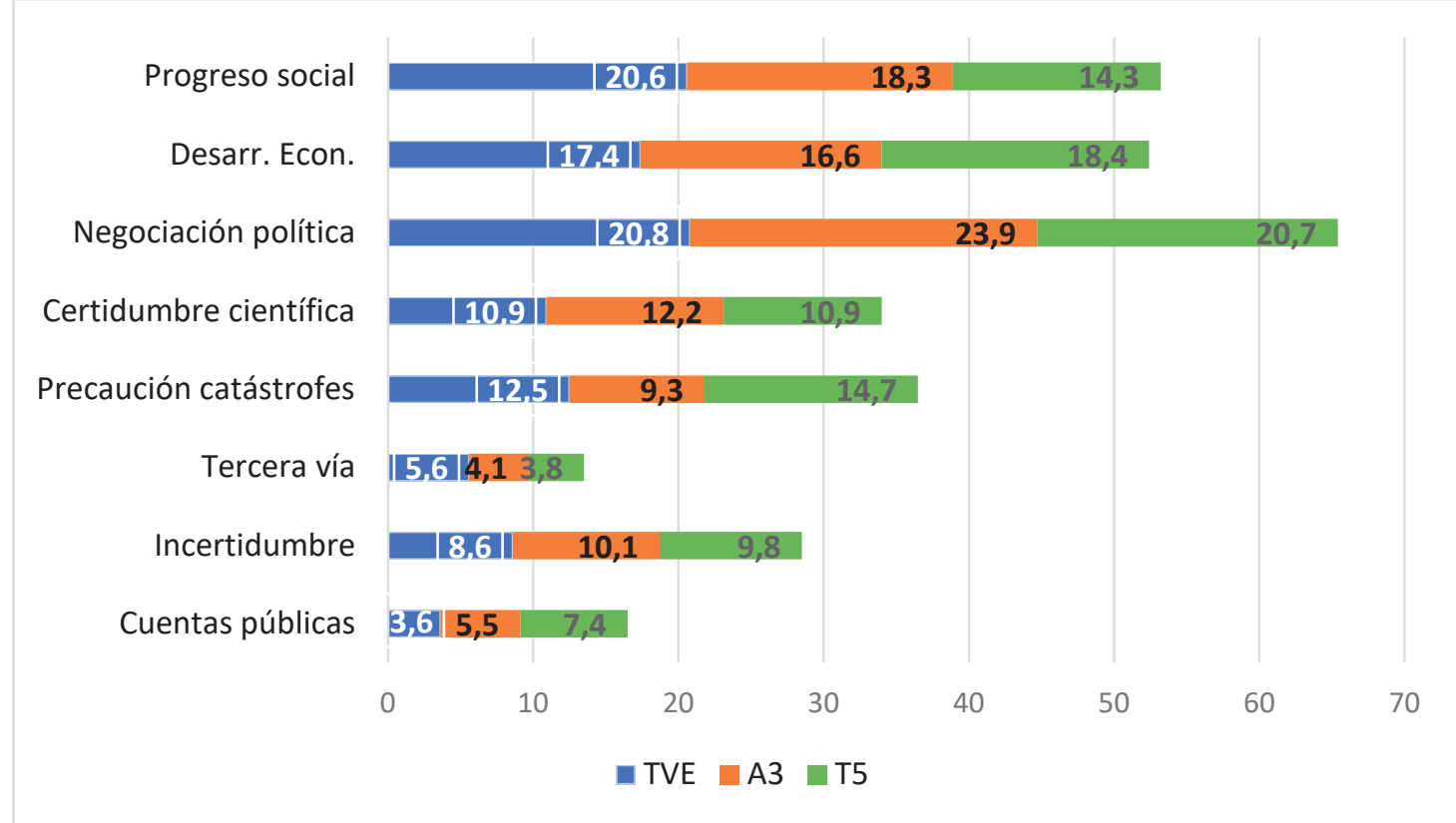

Figura 9. Encuadre informativo por cadenas.

Fuente: elaboración propia.

Las tres cadenas presentan un comportamiento similar respecto a la divulgación científica y parecen apostar en sus informaciones por poner en valor la relevancia de la Ciencia como base del conocimiento, así como el rol que juega la innovación parar encontrar soluciones al reto ambiental. Se acaba con el framing en las noticias del cambio climático presente en la cobertura informativa de cumbres anteriores, especialmente Cancún y Durban, en lo relativo a la espectacularización de la información y en poner el acento en imágenes de aspectos desastrosos (Águila, 2016).

En referencia a los impactos del cambio climático, éste ha sido tratado de forma directa en el $16,5 \%$ de las informaciones, es decir, en un total de 39 piezas (11 Telecinco, 12 Antena 3 y 16 TVE). Un porcentaje que asciende al $54,9 \%$ de las informaciones si sumamos aquellas noticias en las que se trata el tema de forma indirecta, bien aludiendo a la necesidad de educar a la población y un cambio en los modos de vida para paliar sus efectos, o bien, mediante los discursos de asociaciones ecologistas o la propia Greta Thunberg.

El 92\% de las piezas realiza una identificación del problema y de los responsables del cambio climático, al tiempo que se alude a las consecuencias negativas, fundamentalmente las relativas al aumento de las temperaturas (23\%) y la extinción de las especies (22\%). También son frecuentes las noticias que mencionan las consecuencias económicas (13\%), la subida del nivel del mar (12\%) y las catástrofes extremas (11\%).

Al igual que en cumbres precedentes, el cambio climático es aludido en menor medida como causa de migraciones (7\%), como factor de distribución de enfermedades potencialmente mortales (9\%) y como potenciador de la desigualdad social (3\%). En este sentido, es interesante señalar que mientras que las tres cadenas televisivas presentan un enfoque similar, en la radio cada emisora aborda la cuestión climática desde una perspectiva diferente (De Sola, 2020). 
Telecinco es la cadena que en mayor medida pone el foco de atención en la extinción de especies (25\%) y en el aumento de las temperaturas (26,4\%), mientras que Antena 3 hace hincapié en las consecuencias económicas $(15,7 \%)$, frente al 10\% de TVE. La cadena pública hace referencia al apartheid climático en el 5,6\% sus informaciones y las consecuencias migratorias que posee el cambio climático (10\%) (Ver Figura 10).

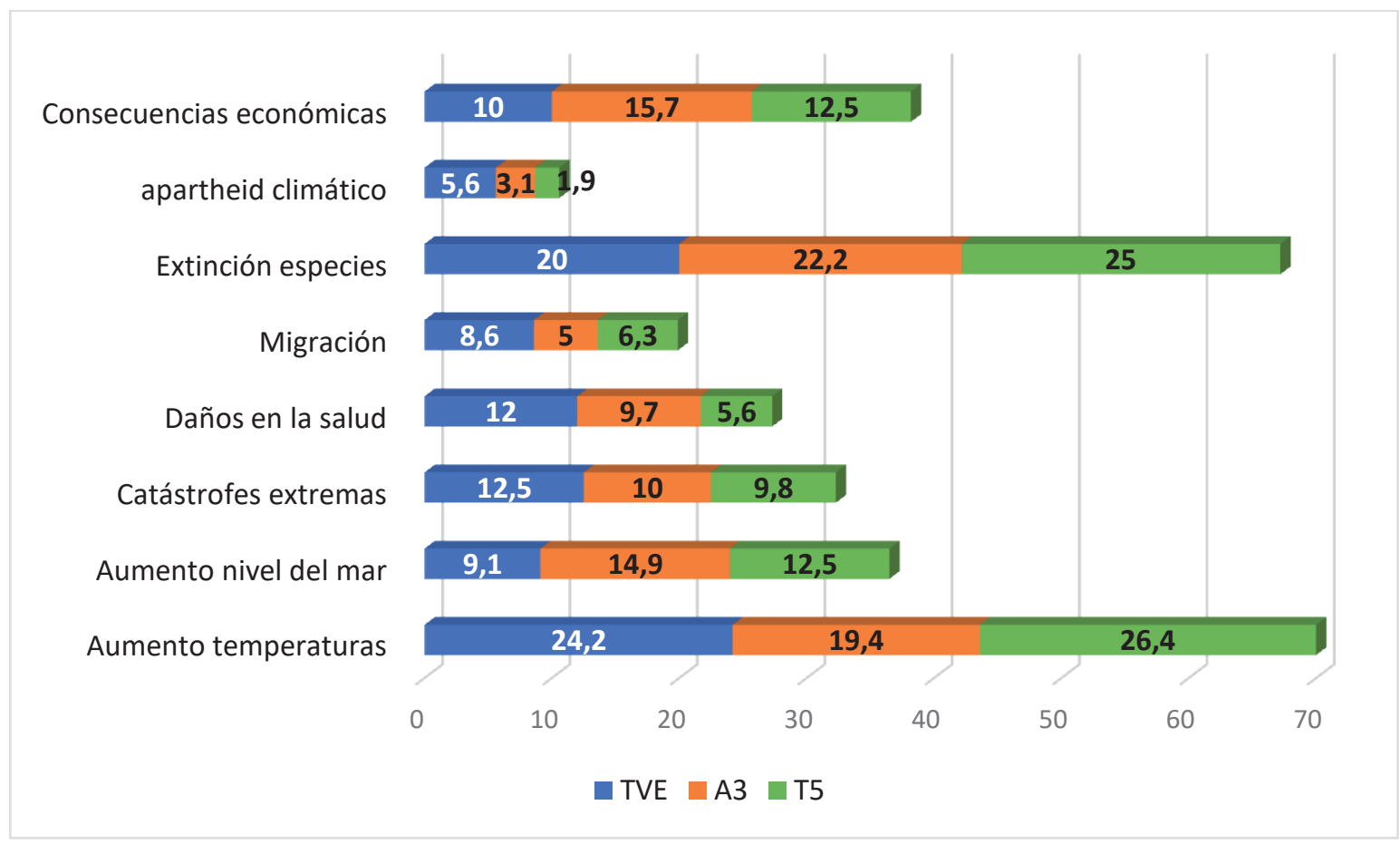

Figura 10. Consecuencias atribuidas al cambio climático por cadenas.

Fuente: elaboración propia.

Pese a que las causas suelen estar bien identificadas, sólo el $68 \%$ de las piezas aborda soluciones y alternativas existentes. En este sentido, destaca TVE (79\%), que presenta el problema como un motor para el cambio social y opta por plantear acciones diarias que contribuyan a una visión positiva del cambio climático, así como a difundir iniciativas que permitan reducir las emisiones.

\section{CONCLUSIONES}

La vigésima quinta Cumbre del Clima ha ocupado un lugar relevante dentro de las parrillas televisivas, especialmente en los informativos del mediodía TVE, Telecinco y Antena 3. Se rompe así, la tendencia informativa decreciente que desde la Cumbre del Clima de Copenhague (2009) se daba en los medios españoles.

El hecho de que, en esta ocasión, el evento internacional haya tenido lugar en Madrid debido a las dificultades de Chile para su organización, ha provocado que las cadenas patrias hayan realizado un ingente esfuerzo para dar cobertura a este encuentro. A nivel cuantitativo, la COP25 retoma con fuerza el interés informativo por el cambio climático, tanto en volumen ( $25 \%$ de los contenidos totales) como en una relevancia que viene marcada por el peso 
específico que ha tenido en la escaleta y por la creación de espacios predeterminados dentro de los noticieros, especialmente en TVE.

Si bien el interés informativo ha ido decreciendo a lo largo de su desarrollo, la presencia de Greta Thunberg ha contribuido a mantener el nivel noticioso, hasta el punto de convertirse en tema informativo de primer nivel, fagocitando, incluso, el papel de los jóvenes en esa Cumbre del Clima y las demandas de los grupos ecologistas.

Otros temas prominentes han sido las negociaciones propias del evento, los informes medioambientales y el cambio climático que, de forma directa o indirecta, se ha convertido en el protagonista de casi el $17 \%$ de las informaciones, siendo TVE la cadena que más lo ha incluido entre sus noticias, identificando en las mismas el origen del problema y proponiendo soluciones e iniciativas para paliar las consecuencias negativas.

La cobertura de la Cumbre ha sido eminentemente informativa (una tendencia también observada en la radio) y de producción propia, con gran presencia de los profesionales de las cadenas en el recinto ferial de Ifema. Resulta significativo el escaso uso de la entrevista como género informativo, sobre todo teniendo en cuenta la cantidad de científicos, políticos y activistas medioambientales, lo cual denota un escaso interés por su punto de vista, que los líderes presenten no resultaran lo suficientemente reseñables o que no accedieran a ellas, como la absoluta protagonista de la Cumbre, Greta Thunberg.

También hay que resaltar la escasa presencia de reportajes dentro del conjunto informativo, siendo Televisión Española la cadena que ha realizado un mayor esfuerzo en este sentido. Pese a ser escasos, destacan por su calidad discursiva y técnica, ya que permiten contextualizar las noticias, comunicar las causas y los impactos, y aportan un contenido transparente gracias al uso de fuentes cualificadas.

Se trata de una narración informativa que permite divulgar la investigación científica en torno al cambio climático y que, además, pone de relevancia las medidas individuales y colectivas que se pueden llevar a cabo para mitigar sus efectos. Esta contextualización resulta de gran relevancia en la medida en que contribuye a la "comprensión de la causalidad sistémica característica de las problemáticas medioambientales y posibilita la formación de estructuras mentales que asimilan la relación entre el comportamiento individual y la mitigación del cambio climático" (Rojo y Dudu, 2017, p. 7).

Este discurso eminentemente informativo, de corte educativo, está presente en más del $40 \%$ de las informaciones, las cuales ofrecen un diagnóstico de la situación desde un punto de vista pedagógico. Esta temática se deja sentir también en los encuadres empleados. El conjunto informativo ha estado dominado por las informaciones relativas al progreso social y los avances científicos y al desarrollo económico que lleva aparejado un cambio en los modos de vida. Las tres cadenas presentan un comportamiento similar respecto a la divulgación científica y parecen apostar en sus informaciones por poner en valor la relevancia de la ciencia como base del conocimiento del cambio climático y sus impactos, así como el rol que juega la innovación parar encontrar soluciones al reto ambiental.

Las negociaciones políticas también han ocupado un lugar preeminente dentro de las noticias, una tendencia ya observada desde la Cumbre de Copenhague y que, en esta ocasión, han estado marcadas por una connotación discursiva negativa ante la incapacidad de los países 
para llegar a acuerdos concretos, aportando planes de futuro y no propuestas de buenas intenciones.

Los resultados de esta investigación presentan una nueva línea discursiva en la práctica periodística de las cadenas televisivas, las cuales se alejan de las posturas catastrofistas dominantes en la cobertura informativa de cumbres precedentes, para convertirse en aliadas en la lucha contra el cambio climático y en ser capaces de "valorar, analizar, comprender y explicar lo que está pasando y, dentro de lo posible, lo que puede pasar, especialmente en aquellos campos que, hasta donde puede preverse hoy, serán los escenarios decisivos de la transición a la nueva sociedad" (Calvo Hernando, 1996).

Queda no obstante por delante el reto de comprobar si las televisiones, de acuerdo con su función social, son capaces de mantener su atención respecto a las cuestiones relacionadas con la crisis climática o si bien se trata de un hecho puntual asociado al interés informativo despertado por una Cumbre mundial organizada por España.

\section{Referencias}

Águila, J.C. y Teso, G. (2011). Aplicación del Protocolo de Registro y Análisis de las noticias sobre el Cambio Climático (CC) en los programas informativos diarios en España [Ponencia]. III Congreso Internacional Latina de Comunicación Social. Universidad de La Laguna, Tenerife, España.

Águila, J. C. (2016). La comunicación del cambio climático: análisis del discurso de los telediarios españoles sobre las cumbres de Cancún y Durban [Tesis doctoral inédita, Universidad Complutense de Madrid]. https://bit.ly/2RJTX7q

Alonso-González, M. (2020). Tiempo y medioambiente como ejes noticiosos en los informativos de TVE, Antena 3 y Telecinco. Miguel Hernández Communication Journal, 11(2), 315-336. http://dx.doi.org/10.21134/mhcj.v11i0.337

Arévalo, C. (2012). Climate Change Summit beyond Copenhagen, Who Goes, Who Stays, and How Are They Covered? University of Oxford.

Bachetta, V. (2012). Perfil del periodista ambiental. Sala de Prensa, 42(2). https://bit.ly/3oEqEyq

Barlovento (2019). Análisis Audiencias TV: Diciembre 2019. https://bit.ly/3nG4U42

Calvo Hernando, Manuel (1996). Panorama de periodismo ambiental en España. APIA.

Cáceres, M.D., Sánchez Calero, M. L. y Morales, E. (2012). La representación televisiva del cambio climático: las noticias sobre la Cumbre de Cancún en las cadenas españolas. Index Comunicación, 2 (1), 113-128.

Cobb, R. y Elder, Ch. (1972). Participation in American Politics: The Dynamics of Agen-da-Building. Johns Hopkins University Press.

Comisión Europea (2020). Consecuencias del Cambio Climático. https://ec.europa.eu/clima/change/consequences_es

CMNUCC (1992). Convención Marco de las Naciones Unidas sobre el Cambio Climático. https://bit.ly/3skEbNS

De Rueda, A. (2014). El discurso político y el tratamiento periodístico del cambio climático en la prensa española durante las Conferencias de las Partes de Naciones Unidad: de Copenhague (2009) a Varsovia (2013). [Tesis doctoral, Universidad Cardenal Herrera- CEU]. Repositorio Institucional CEU. https://repositorioinstitucional.ceu.es/handle/10637/7389

De Sola, J. (2020). La cobertura de la Cumbre del Clima Chile Madrid COP25 en los informativos de la radio española. adComunica. Revista Científica del Estrategias, Tendencias e Innovación en Comunicación, 20, 205-230. DOI: http://dx.doi.org/10.6035/2174-0992.2020.20.9. 
Digital News Report (2020). Los medios afrontan los retos de recuperar una confianza debilitada y seguir ampliando ingresos por suscripciones. https://www.digitalnewsreport.es/

Ertivi, C. y De Lara, A. (2012): Las imágenes televisivas del cambio climático. Estudio de la cobertura de la Cumbre de Durban en los informativos españoles. Revista Comunicación, 10, 1466-1481.

Escudero, L., Lois, R. y Martí, A. (1999). La cuestión del cambio climático, realidad y noticia. Una aproximación desde el territorio gallego. Revista de Geografía, 32, 67-78.

Fahn, J. (2008). Rescuing reporting in the global South. Media coverage of climate change lags behind in the countries where it matters most. Nature Reports Climate Change, 2, 88-90.

Fernández, J. (2001). Dos siglos de periodismo Ambiental. Caja de Ahorros del Mediterráneo.

Fernández Parrat, S. (2006). La Información Ambiental en los medios de comunicación. Telos, 68, 1-10.

Fernández-Reyes, R., Piñuel-Raigada y Mariño, M. (2015). La cobertura periodística del cambio climático y el calentamiento global en el El País, el Mundo y la Vanguardia. Revista Latinoamericana de Comunicación Social, 70, 122-140. https://doi.org/10.4185/RLCS-2015-1038.

Francescutti, L. P., Tucho Fernández, F. e Íñigo Jurado, A. I. (2013). El medio ambiente en la televisión española: análisis de un año de informativos. Estudios sobre el Mensaje Periodístico, 19 (2), 683-701.

Heras, F., Meira, P. y Benayas, J. (2016). Un silencio ensordecedor. El declive del cambio climático como tema comunicativo en España 2008-2012. Redes.com: revista de estudios para el desarrollo social de la Comunicación, 13, 31-54.

Jiménez Gómez, I. (2017). Hablemos del tiempo. El imaginario publicitario del cambio climático. Ámbitos, 37, 1-12. http://dx.doi.org/10.12795/Ambitos.2017.i37.04

Ladle, R., Jepson, P. y Whittaker, R. (2005). Scientists and the media: the struggle for legitimacy in climate change and conservation science. Interdisciplinary Science Reviews, 30(3), 231-240. https://doi.org/10.1179/030801805X42036

León, B. (Coord.) (2016). El medio ambiente en el nuevo universo audiovisual. UOC

León, B y De Lara, A. (2013). Ciencia y cambio climático. Estudio de la cobertura del cambio climático en la prensa española, en R. Fernández-Reyes (dir.) y R. Mancinas (coord.), Libro de Actas de las Jornadas Internacionales Medios de Comunicación y Cambio Climático (pp.91-104). Fénix Editora.

León, B. y Erviti, M. (2011). Portrayal of scientific controversy on climate change. A study of the coverage of the Copenhagen summit in the Spanish press. Observatorio Journal, 5(3), 45-63.

León, B. y Erviti, C. (2013). Science in pictures. Visual representation of climate change in Spain's television news. Public Understanding of Science, 24(2), 183-199.

Lizcano, J. L. (2009). Hacia una normalización de la información corporativa. El reporte de RSC y los sistemas de verificación. Cuaderno Telos, 79.

Lomborg, B. (2003). El ecologista escéptico. Espasa Calpe.

Lopera, E. (2013): La Comunicación social de la ciencia del clima en la prensa española: texto y contexto. Colección Documentos Ciemat.

Lorente, J. I., Antolín, J. E., Doblas, F.J. (2009). La construcción mediática de lo ecológico. Estrategias discursivas en la información de actualidad. Revista Latina de Comunicación Social, 64, 315-327.

Macinas, R. (2013). El silencio mediático. Reflexión en torno a las razones de los medios de comunicación para no hablar del cambio climático, en R. Fernández-Reyes (dir.) y R. Mancinas (coord.), Libro de Actas de las Jornadas Internacionales Medios de Comunicación y Cambio Climático (pp. 233-248). Fénix Editora.

Mercado, M. (2013). El análisis del tratamiento informativo del cambio climático, en R. Fernández-Reyes (dir.) y R. Mancinas (coord.), Libro de Actas de las Jornadas Internacionales Medios de Comunicación y Cambio Climático (pp. 123-134). Fénix Editora. 
Moreno, P. (2012). El reportaje televisivo y sus interpretaciones de la realidad. Estudios sobre el Mensaje Periodístico,18 (2), 823-832.

Nisbet, M. C. (2009). Communicating climate change: Why frames matter for public engagement. Environment: Science and Policy for Sustainable Development, 51(2), 12-23.

Nossek, H. y Kunelious, R. (2012): News flows, Global Journalim and Climate Summits, en E. Eide y R. Kunnelius (eds.), Medida Meets Climate (pp.67-85). Nordicom.

Pew Research Center (2019). Climate Change Still Seen as the Top Global Threat, but Cyberattacks a Rising Concern. https://pewrsr.ch/3nzT9ME

Picó Garcés, J. M: (2017). Periodismo ambiental: de la lucha ecologista al entorno digital. UOC.

Piñuel, J. L., Gaitán, J. A. y Lozano, C. (2012). Los telediarios ante el cambio climático. La deriva de la información sobre la catástrofe en las cumbres del clima y en tiempos de calma [ponencia], IV Congreso Internacional Latina de Comunicación Social. Universidad de La Laguna, Tenerife, España.

Reig, R. (2010). Condicionantes estructurales del trabajo del periodista: las causas de una sociedad desinformada. Global Media Journal, 7(14), 39-59.

RTVE (2019). Un telediario del futuro. Recuperado de https://bit.ly/3sfh8UJ.

Ripple, W., Wolf. C., Newsome, T., Barnard P. y Moomaw, W. (2019). World Scientists' Warning of a Climate Emergency. BioScience, 69 (11). https://doi.org/10.1093/biosci/biz088

Rodríguez Cárcela, R. (2011). La información de sucesos. Temática en prensa escrita. Correspondencias \& Análisis, 1, 309-325.

Rojo, T. y Dudu, S. (2017). Los videojuegos en la implementación de políticas de mitigación del cambio climático. Ámbitos, 37, 1-23. http://dx.doi.org/10.12795/Ambitos.2017.i37.06

Sánchez Calero, Ma L., Morales, E. y Cáceres, Ma․ D. (2012). La cobertura televisiva de la cumbre de Cancún: Agenda Temática, discursos y fuentes en los informativos españoles. Index Comunicación, 2, 113-128.

Semetko, H.A. y Valkenburg, P. M. (2000): Framing european politics: analysis of press and TV news. Journal of Communication, 1, 93-109.

Tankard, J. W. (2001). The empirical approach to the study of media framing, en S. D. Reese, D. Stephen, O.Gandy, y A.Grant. (eds.), Framing public life. Perspectives on media and our understanding of the social world (pp.95-106). Lawrence Erlbaum Associates.

Teso, G. (2016). Comunicación y representaciones del cambio climático: el discurso televisivo y el imaginario de los jóvenes españoles. [Tesis doctoral, Universidad Complutense de Madrid. Madrid]. https://eprints.ucm.es/41736/

Teso, G., Fernández-Reyes, R., Gaitán Moya, J. A., Lozano Asencio, C. y Pinuel Raigada, J. L. (2018). Comunicación para la sostenibilidad: el cambio climático en los medios. Fundación Alternativas.

Kolberte, E. (2006). Field notes from a catastropher: man, nature an climate change. Blomsbury.

Vicente, M. y López, P. (2009). Resultados de la investigación en comunicación sobre framing: sólido avance y arranque de la especialidad en España. ZER, 26, 13-34.

\section{Semblanza de la autora}

Marián Alonso-González es Doctora en Comunicación por la Universidad de Sevilla (2008) con una Tesis Doctoral que versa sobre el cambio tecnológico de ABC de Sevilla. Miembro de la Asamblea de Mujeres Periodistas de Sevilla y del Censo de Expertas, compagina su labor profesional como Técnico de Comunicación en Adif con su labor docente como profesora asociada en la Facultad de Comunicación de Sevilla, donde imparte clases de nuevas 
tecnologías y redacción. Especializada en redes sociales, ha orientado su investigación a campos relacionados con la Comunicación 2.0, el Periodismo 3.0, las audiencias sociales y los nuevos lenguajes multimedia e interactivos. 